\title{
Metabolic changes associated with the occurrence of fatty liver and kidney syndrome in chicks
}

\author{
BY C. C. WHITEHEAD, D. W BANNISTER \\ AND MAUREEN E. CLELAND \\ Agricultural Research Council's Poultry Research Centre, \\ King's Buildings, West Mains Road, Edinburgh EH9 3 JS
}

(Received I9 September 1977-Accepted 4 January 1978)

\begin{abstract}
I. The changes in a number of metabolic measurements brought about by low-biotin diets associated with high and low incidences of fatty liver and kidney syndrome (FLKS) were studied in healthy 4-week-old broiler chicks.

2. Liver pyruvate carboxylase (pyruvate: $\mathrm{CO}_{2}$ ligase (ADP); EC 6.4.I.I) activity was low in birds fed on a diet causing a high incidence of FLKS but the addition of fat or protein to this diet, to decrease the incidence of FLKS, increased enzyme activity.

3. Liver weights, blood lactate concentrations, plasma lactate dehydrogenase (L-lactate:NAD oxidoreductase; $E C$ 1.1.I.27) activities and values for $\mathrm{C}_{16: 1}: \mathrm{C}_{18: 0}$ fatty acid in liver, adipose tissue and plasma triglyceride were highest in birds fed on the high-FLKS diet and all measurements were negatively correlated with pyruvate carboxylase activity.

4. Birds with high plasma lactate dehydrogenase activity or triglyceride $C_{16: 1}: C_{18: 0}$ values were the most likely to develop FLKS when fasted.

5. There was no evidence that increased liver weight was associated with increased activities of certain other liver enzymes.

6. It is concluded that FLKS occurs in birds with little or no hepatic gluconeogenic capacity via pyruvate carboxylase as a result of a dietary insufficiency of biotin but that the initiation of the syndrome is probably associated with the inhibition of other pathways of gluconeogenesis.
\end{abstract}

Fatty liver and kidney syndrome (FLKS) is a metabolic disorder that kills young chickens fed on diets of low biotin content. Its incidence can be reduced by increasing the level of dietary fat (Whitehead, Blair, Bannister \& Evans, 1975) or protein (Whitehead \& Blair, 1974,1976 ) and eliminated by supplementing the diet with biotin (Blair \& Whitehead, 1974; Payne, Gilchrist, Pearson \& Hemsley, 1974; Whitehead, Blair, Bannister, Evans \& Jones, 1976). The syndrome is characterized by an accumulation of lipid in liver, kidney and other organs (Wight \& Siller, 1975) and a severe hypoglycaemia which is thought to be the probable cause of death (Bannister, Evans \& Whitehead, 1975). However, these changes occur only after initiation of the syndrome (Evans, Bannister, Whitehead, Siller \& Wight, 1977) which is sudden and apparently precipitated by stress or starvation (Whitehead et al. 1975).

A major cause of the hypoglycaemia is failure of hepatic gluconeogenesis, brought about by a very low activity of pyruvate carboxylase (pyruvate: $\mathrm{CO}_{2}$ ligase (ADP); EC 6.4.I. I), a biotin-dependent enzyme, and it has been shown both in vitro and in vivo that addition of biotin will restore gluconeogenesis by increasing the activity of this enzyme (Bannister, $1976 a, b)$.

The condition is therefore dependent on a dietary insufficiency of biotin. However, the manifestations of the syndrome are quite distinct from those of typical biotin deficiency, although symptoms of the two conditions can co-exist (see Payne et al. 1974; Lohr, 1975) and the specific metabolic changes brought about by a lack of biotin that are associated with the development of susceptibility to the syndrome have not been established. Hood, Johnson, Fogarty \& Pearson (1976) have suggested that, in a marginal deficiency of dietary biotin, pyruvate carboxylase activity becomes insufficient to metabolize pyruvate via 
Table I. Composition $(\mathrm{g} / \mathrm{kg})$ of experimental diets

\begin{tabular}{|c|c|c|c|c|c|}
\hline Ingredient & $\mathbf{I}$ & 2 & 3 & 4 & 5 \\
\hline Wheat & 650 & 650 & 650 & 650 & \\
\hline Soya-bean meal $(445 \mathrm{~g} \mathrm{CP} / \mathrm{kg})$ & 100 & 100 & 100 & 100 & \\
\hline Herring meal & 63 & 63 & 63 & 63 & \\
\hline Maize starch & 125 & - & 85 & 125 & \\
\hline Maize oil & $1 \cdot 5$ & 50 & $\mathrm{I} \cdot 5$ & I.5 & \\
\hline Isolated soya-bean protein* & 31 & 31 & $3 I$ & $3 \mathrm{I}$ & \\
\hline Amino acid mixture $\dagger$ & - & - & 40 & - & \\
\hline Cellulose & - & 75 & - & - & T \\
\hline Limestone flour & 16 & 16 & 16 & 16 & \\
\hline Dicalcium phosphate & II. 5 & $11 \cdot 5$ & $11 \cdot 5$ & II. 5 & \\
\hline Salt & 2 & 2 & 2 & 2 & \\
\hline Mineral supplement $\ddagger$ & $2 \cdot 5$ & $2 \cdot 5$ & 2.5 & $2 \cdot 5$ & \\
\hline Vitamin supplement $\S$ & $2 \cdot 5$ & $2 \cdot 5$ & $2 \cdot 5$ & $2 \cdot 5$ & \\
\hline Rovimix $\mathbf{H} \|$ & - & - & 0.07 & - & \\
\hline \multicolumn{6}{|l|}{ Chemical analysis } \\
\hline $\mathrm{CP}$ & 179 & 181 & 218 & 179 & 200 \\
\hline Diethyl ether extract & 18 & 70 & 19 & 18 & 35 \\
\hline \multicolumn{6}{|c|}{ 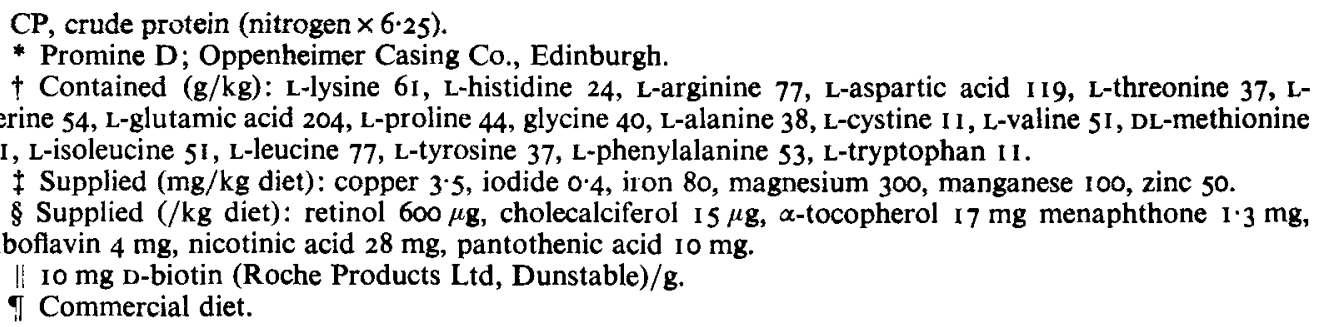 } \\
\hline
\end{tabular}

Diet no. 
Diets

Details of the five experimental diets are given in Table I. Diet no. I was the wheat-based low-fat, low-protein diet which had been found from a series of experiments to cause a high spontaneous incidence of mortality (20-30\%) from FLKS (Whitehead \& Blair, 1976). Microbiological analyses (Wright \& Skeggs, 1944) showed it to contain approximately $0.10 \mathrm{mg}$ total biotin $/ \mathrm{kg}$, but probably only $0.06-0.07 \mathrm{mg} / \mathrm{kg}$ of this was available to the chick. Diets nos. 2 and 3 were modifications of diet no. $\mathrm{I}$ in which either the fat or the protein level was increased by the addition of maize oil or a crystalline amino acid mixture respectively, at the expense of starch. Cellulose was used as an inert filler in diet no. 2 so that both diets had the same metabolizable energy and biotin levels as diet no. I. However, previous studies have shown that they caused less mortality $(5-10 \%)$ from FLKS (Whitehead et al. 1975; Whitehead \& Blair, 1976). Two control diets were also used. Diet no. 4 was diet no. I supplemented with $0.70 \mathrm{mg}$ biotin $/ \mathrm{kg}$ but, because it had lower fat and protein levels than are normally given to young broilers, the second control diet, diet no. 5, was a normal commercial chick starter diet (Scottish Agricultural Industries Ltd, Edinburgh $\left.\mathrm{EH}_{4}{ }_{3} \mathrm{ET}\right)$ thought to be adequate in all nutrients.

\section{Procedure}

Expt I. For analytical reasons the experiment was carried out as a series. Birds were reared from I-d-old on each of five diets on a regular basis and each week analyses were carried out on one apparently healthy 28 -d-old chick taken from each of only three diets according to a randomized plan. The experiment continued until results had been obtained for eighteen birds fed on diet no. I and for nine fed on each of the other diets. On selection, each bird was kept quiescent in the dark for $20 \mathrm{~min}$, then it was weighed and a blood sample $(\mathrm{I} O \mathrm{ml})$ was collected in a heparinized vessel. The bird was killed and the liver was removed, placed immediately in a tared beaker of ice-cold saline ( $9 \mathrm{~g}$ sodium chloride/l) and weighed.

Blood lactate, pyruvate and plasma lactate dehydrogenase (L-lactate:NAD oxidoreductase; $E C$ I. I I . 27) were measured immediately. In some instances plasma was frozen before measurement of glucose concentration or triglyceride. Liver enzyme activities were measured on fresh tissue. A liver sample was also frozen and freeze-dried before lipid analyses. Samples of liver, kidney and heart were fixed in formal saline (100 ml/l) for subsequent histological examination. A sample of peritoneal adipose tissue was also kept frozen until its fatty acid composition was determined.

Expt 2. Twenty chicks were reared from I-d-old on each of diets nos. I and 4. At 4 weeks of age the birds were weighed and a blood sample $(5 \mathrm{ml})$ was taken from a wing vein with a heparinized syringe for measurement of lactate and glucose concentrations. The birds were fasted for $6 \mathrm{~h}$, after which time the condition of each bird was noted and a further blood sample was taken. The birds were killed and samples of liver and kidney were fixed for histological examination.

Expt 3. Thirty healthy 4-week-old chicks reared on diet no. I were weighed and blood samples $(3 \mathrm{ml})$ were taken in a heparinized syringe from the wing vein for measurement of triglyceride fatty acid composition, lactate dehydrogenase activity and glucose concentration. After a $6 \mathrm{~h}$ fast, a second blood sample was taken for glucose analysis, the birds were killed and samples of liver and kidney were taken for histological examination.

\section{Analytical methods}

Enzyme assays. Hepatic malate dehydrogenase was assayed by the method of Wise \& Ball (1964). Tissue was disrupted in a Potter-Elvehjem homogenizer (in ice) in 0.25 M-sucrose 
(200 mg wet weight $/ \mathrm{ml}$ ) and centrifuged at $40000 \mathrm{~g}$ for $10 \mathrm{~min}$ at $2^{\circ}$. A portion of the supernatant fraction was diluted $\mathrm{I}: 4(\mathrm{v} / \mathrm{v})$ with bovine serum albumin $(0.1 \mathrm{~g} / \mathrm{l} ; 0.0 \mathrm{Iml})$ and was assayed in a medium (final volume $2.3 \mathrm{I} \mathrm{ml}$ ) containing: $22 \mathrm{mM}$-Tris buffer (adjusted to $\mathrm{pH} 7.4$ at $38^{\circ}$ with hydrochloric acid), $0.78 \mathrm{~mm}$-sodium malate, $8.8 \mathrm{~mm}-\mathrm{MgCl}_{2}, 0.52 \mathrm{~mm}$ NADP. The reaction was started by the addition of substrate after equilibration at $38^{\circ}$ for $10 \mathrm{~min}$. Enzyme activity was monitored by measuring the extinction at $340 \mathrm{~nm}$ using a spectrophotometer (SP 30 double-beam; Pye Unicam, Cambridge). Measurements taken every $30 \mathrm{~s}$ between $I$ and $4 \mathrm{~min}$ were used to calculate the change in extinction $/ \mathrm{min}$.

Lactate dehydrogenase activity in plasma and liver tissue was assayed by the method of Bergmeyer \& Bernt (1974). Plasma (0.05 ml) was assayed in a medium (final volume $3.15 \mathrm{ml}$ ) containing: $48 \mathrm{~mm}$-phosphate buffer ( $\mathrm{pH} 7 \cdot 0), 0.3 \mathrm{I} \mathrm{mM-NADH,} \mathrm{I.2} \mathrm{mM-sodium} \mathrm{pyruvate.}$ The samples were allowed to equilibrate at $38^{\circ}$ for $20 \mathrm{~min}$ and the reaction was initiated by addition of substrate. Liver tissue homogenates were prepared in $0.6 \mathrm{M} \cdot$ sucrose $(200 \mathrm{mg}$ wet weight $/ \mathrm{ml}$ ) and centrifuged at $40000 \mathrm{~g}$ for 10 min at $2^{\circ}$. A portion of the supernatant fraction, diluted $\mathrm{I}: 50(\mathrm{v} / \mathrm{v})$ with bovine serum albumin $0.1 \mathrm{~g} / 1 ; 0.03 \mathrm{ml})$, was assayed in a medium (final volume $3.13 \mathrm{ml}$ ) containing: $64 \mathrm{~mm}$-phosphate buffer $(\mathrm{pH} 7.0$ ), $0.6 \mathrm{~mm}$ sodium pyruvate, $0.42 \mathrm{~mm}-\mathrm{NADH}$. Samples were allowed to equilibrate for $10 \mathrm{~min}$ at $38^{\circ}$ and the reaction was started by addition of substrate. Enzyme activities were monitored by measuring extinction at $340 \mathrm{~nm}$ as described for malate dehydrogenase.

Acetyl-CoA carboxylase was assayed as follows. Portions of liver were homogenized in a medium comprising $0.25 \mathrm{M}$-sucrose, $10 \mathrm{mM}$-phosphate buffer ( $\mathrm{pH} 7.5$ ), 5 mM-mercaptoethanol, $0^{\circ}$ I mM-EDTA to give a final tissue concentration of $100 \mathrm{mg}$ wet weight $/ \mathrm{ml}$. The homogenate was centrifuged at $40000 \mathrm{~g}$ for $10 \mathrm{~min}$ at $2^{\circ}$, and a portion of the supernatant fraction was assayed immediately in a medium (final volume $\mathrm{I} \mathrm{ml}$ ) containing $(\mu \mathrm{M})$ : Tris buffer 50 (adjusted to $\mathrm{pH} 7.5$ at $38^{\circ}$ with $\mathrm{HCl}$ ), ATP $4, \mathrm{MgCl}_{2} 8, \mathrm{NaH}^{14} \mathrm{CO}_{2}(0.5 \mu \mathrm{Ci})$ I0, glutathione 3 , acetyl CoA 0.4 , DL-isocitric acid 20, bovine serum albumin $6 \mathrm{mg}$. The reaction was initiated by the addition of enzyme preparation $(0.05 \mathrm{ml})$ and the incubation was terminated after $5 \mathrm{~min}$ by the addition of $0.5 \mathrm{ml}$ trichloroacetic acid solution ( $\mathrm{I} 00 \mathrm{~g} / \mathrm{l})$. The precipitated protein was removed by centrifugation at $2500 \mathrm{~g}$ for $10 \mathrm{~min}$. A portion $(0.5 \mathrm{ml})$ of the supernatant fraction was taken to dryness under reduced pressure and the residue was dissolved in $0.5 \mathrm{ml}$ hyamine hydroxide ( $100 \mathrm{~g} / 1$ methanol) and $4 \mathrm{ml} 2,5$-diphenyloxazole $(4 \mathrm{~g} / 1$ toluene-Triton $\mathrm{X}-\mathrm{I} O 0 \mathrm{O}(4: \mathrm{I}, \mathrm{v} / \mathrm{v}))$ and its radioactivity content determined. The incorporation of ${ }^{14} \mathrm{CO}_{2}$ was corrected by subtracting the radioactivity of a control from which acetyl CoA was omitted.

Pyruvate carboxylase activity in liver homogenates was measured as described by Bannister $(1976 b)$.

Blood metabolites. Lactate and pyruvate levels in blood were assayed using Boehringer reagent kits (Boehringer Corporation (London) Ltd, East Sussex BN7 ILG) and methods based on those described by Hohorst (1963) and Czok \& Lamprecht (I970).

Plasma glucose was assayed by the method of Morley, Dawson \& Marks (I968).

Protein analysis. Protein analyses on liver homogenates were carried out using an automated version of the method of Lowry, Rosebrough, Farr \& Randall (195I).

Lipid analysis. Lipids were extracted by the method of Folch, Lees \& Sloane Stanley (1957). Triglycerides were isolated by thin-layer chromatography using the method of Christie, Noble \& Moore (1970). Methyl esters of fatty acids were prepared by transesterification in methanolic hydrogen chloride $(50 \mathrm{ml} / \mathrm{l})$ and estimated by gas-liquid chromatography on a column of 100 g SP 2340/1 Chromosorb W (100-1 20 mesh, acid-washed; Chromatography Services Ltd, Wirral, Merseyside) at $185^{\circ}$ using a flame ionization detector (model 1700; Varian Associates Ltd, Walton on Thames KTI2 2QF).

Chemicals. All chemicals were of analytical or reagent grade and were used as supplied 
(British Drug Houses, Poole, Dorset) except for the Tris buffer used in the acetyl-CoA carboxylase and pyruvate carboxylase assays, which was recrystallized as described by Sutherland \& Waselait (1956). Purified enzymes, coenzymes and adenylates were purchased from Boehringer Corporation (London) Ltd, and from Sigma (UK) Ltd, Kingston upon Thames $\mathrm{KT}_{2}{ }_{7} \mathrm{BH}$. $\mathrm{NaH}^{14} \mathrm{CO}_{2}(0.1 \mathrm{mCi} / \mathrm{mmol})$ was obtained from the Radiochemical Centre, Amersham, Bucks.

\section{RESULTS}

\section{Expt I}

Throughout the experiment there was a $15 \%$ incidence of mortality from FLKS among birds fed on diet no. I, but for each of diets nos. 2 and 3 mortality was only $3 \%$. There were no deaths from FLKS among birds fed on either of the control diets. At 4 weeks of age the birds fed on diets nos. I, 2 and 3 showed foot lesions characteristic of mild biotin deficiency but none was considered to be suffering from FLKS, using clinical appearance of bird, histological appearance of tissues and blood glucose concentration as criteria.

Results for the various liver measurements are set out in Table 2. Mean pyruvate carboxylase specific activity was much lower among birds fed on the low-biotin diets than in controls and was lowest in birds fed on the low-fat, low-protein diet (diet no. I). Acetyl-CoA carboxylase specific activity was significantly lower $(P<0.05)$ with the commercial control diet (diet no. 5) than with diet no. I, but differences between other diets were not significant. Lactate dehydrogenase specific activity was significantly higher $(P<0.001)$ with control diet no. 4 than with all the other diets. The specific activity of malate dehydrogenase was considerably affected by diet: the activity with diet no. I was significantly higher $(P<0.05)$ than with diets nos. 2 and 3 and significantly lower $(P<0.05)$ than with diet no. 4.

Liver weight, as a proportion of body-weight, was significantly higher $(P<0.05)$ in birds fed on diet no. I than on the other diets and the proportion of liver protein was higher with all low-biotin diets than with control diets. Although liver lipid level was unaffected by the different dietary compositions, fatty acid composition was markedly altered. The most pronounced changes were increases in the proportions of monounsaturated fatty acids, especially $C_{18: 1}$, at the expense of the saturated fatty acids, mainly $C_{18: 0}$, in birds fed on the low-biotin diets. $C_{16: 1}: C_{18: 0}$ was taken as the best index of these changes and was highest in the triglyceride fraction of birds fed on diet no. I.

Birds fed on diet no. I were divided into two groups on the basis of their hepatic pyruvate carboxylase specific activities. This division was made because a previous study by Bannister $(1976 b)$, using the same assay technique, had found that birds suffering from FLKS had specific activities of less than $60 \mu \mathrm{mol} / \mathrm{h}$ per $\mathrm{g}$. The 'low' group comprized ten birds with activities of $\leqslant 58 \mu \mathrm{mol} / \mathrm{h}$ per $\mathrm{g}$. The other eight birds, with activities ranging from 70 to $531 \mu \mathrm{mol} / \mathrm{h}$ per g, made up the 'high' group. Results for the liver criteria for these two groups are also included in Table 2 . The only significant difference between them was the liver triglyceride $C_{16: 1}$ : $C_{18: 0}$ value which was higher in the 'low' group.

Results for the blood and adipose tissue criteria are given in Table 3. Blood lactate concentration was significantly higher $(P<0.05)$ among birds fed on diet no. I than among those fed on the corresponding biotin-supplemented control diet (diet no. 4). Pyruvate concentration also varied, though not significantly, with the result that lactate:pyruvate values were very similar. Because the blood lactate:pyruvate value is known to be closely related to that of the liver and hence to the redox state of the organ, the results suggested that the low hepatic pyruvate carboxylase specific activities observed with diet no. I were not impairing the birds' ability to maintain a normal redox state. Plasma glucose concentration was unaffected by diet but lactate dehydrogenase activity was higher $(P<0.05)$ in birds fed on diet no. I than in those on diets nos. 2 or 4 . Plasma and adipose triglyceride 


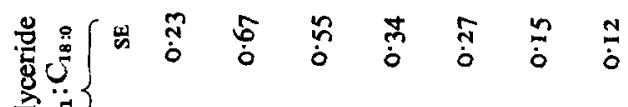

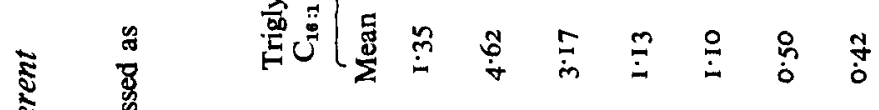

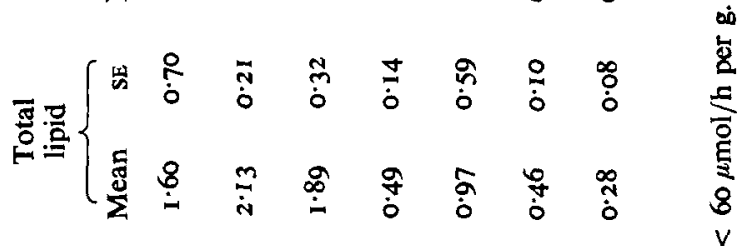

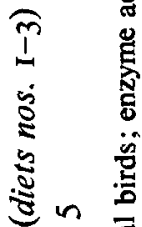

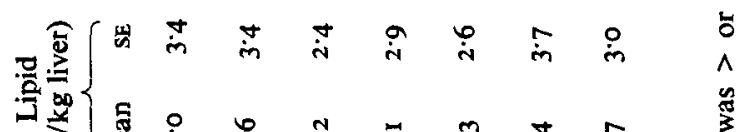

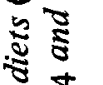

站

:

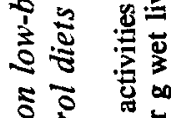

ป

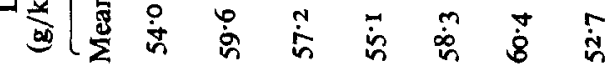

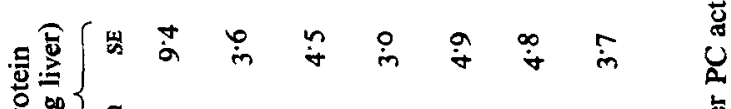

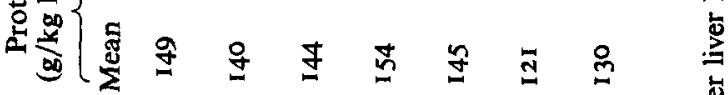

章

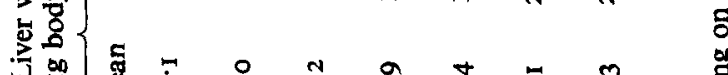

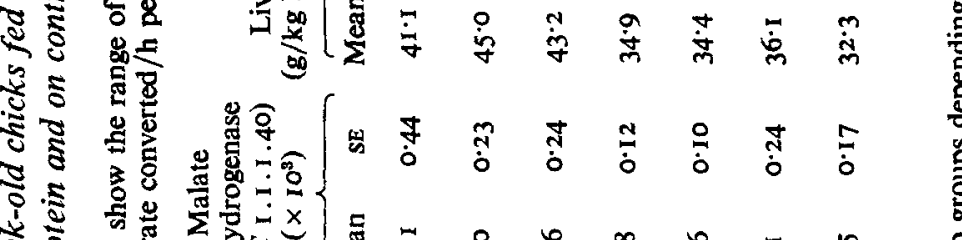

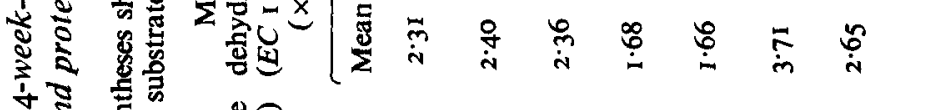

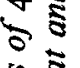

这

焉

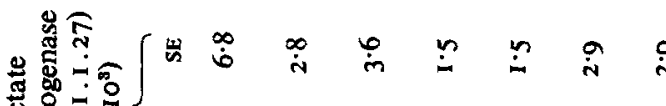

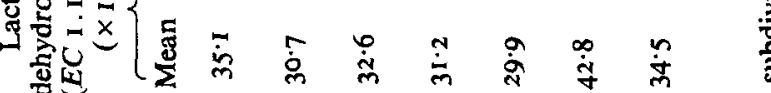

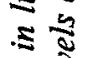

\&

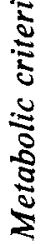

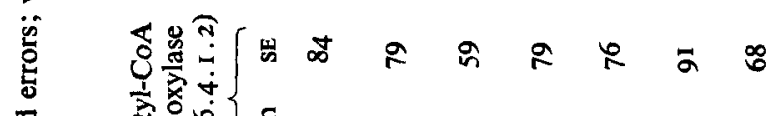

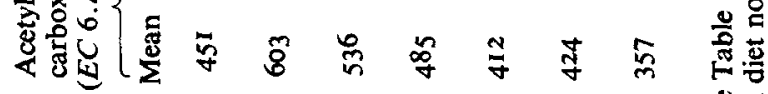

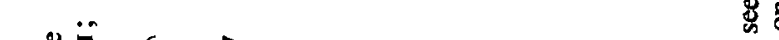

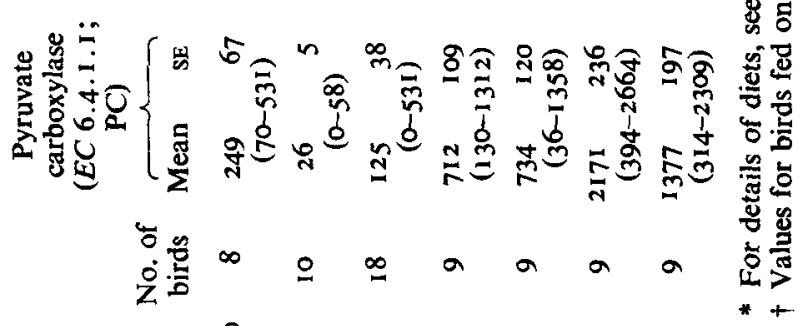

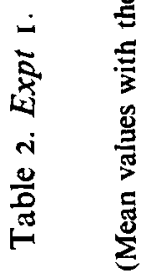

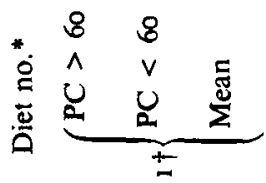


I

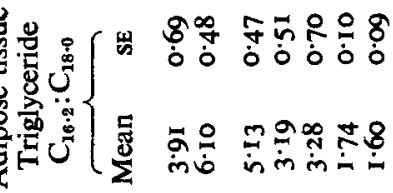

递怘

焉售

$\frac{1}{8}$

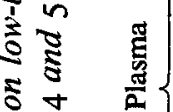

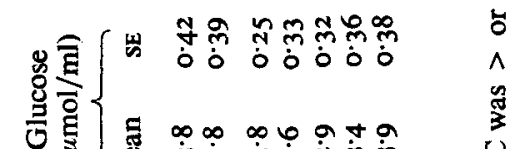

s

$\sum_{\substack{5 \\ 5}}$

$\frac{\pi}{3} \frac{\pi}{2}$

용

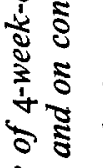

密

\&

ริ

造

$\frac{2}{2} \sum^{\frac{2}{2}}$

ล

ชิ ญे

$5:-$

.28

$\cdot \sqrt{2} \cdot \sqrt{2}$

$\frac{2}{2}$

范

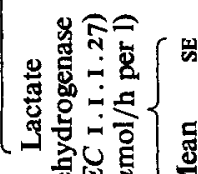

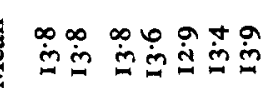

$\stackrel{2}{3}$

논동은

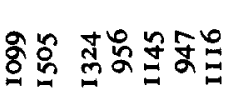

:

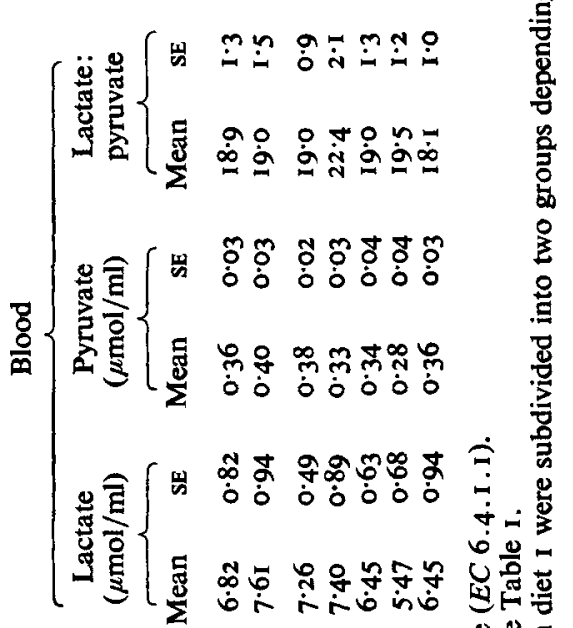

语

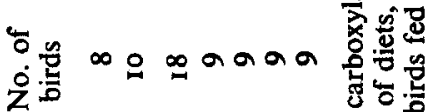

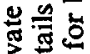

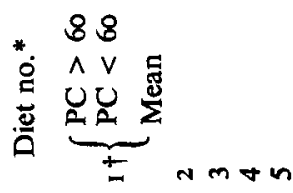

西要

논 


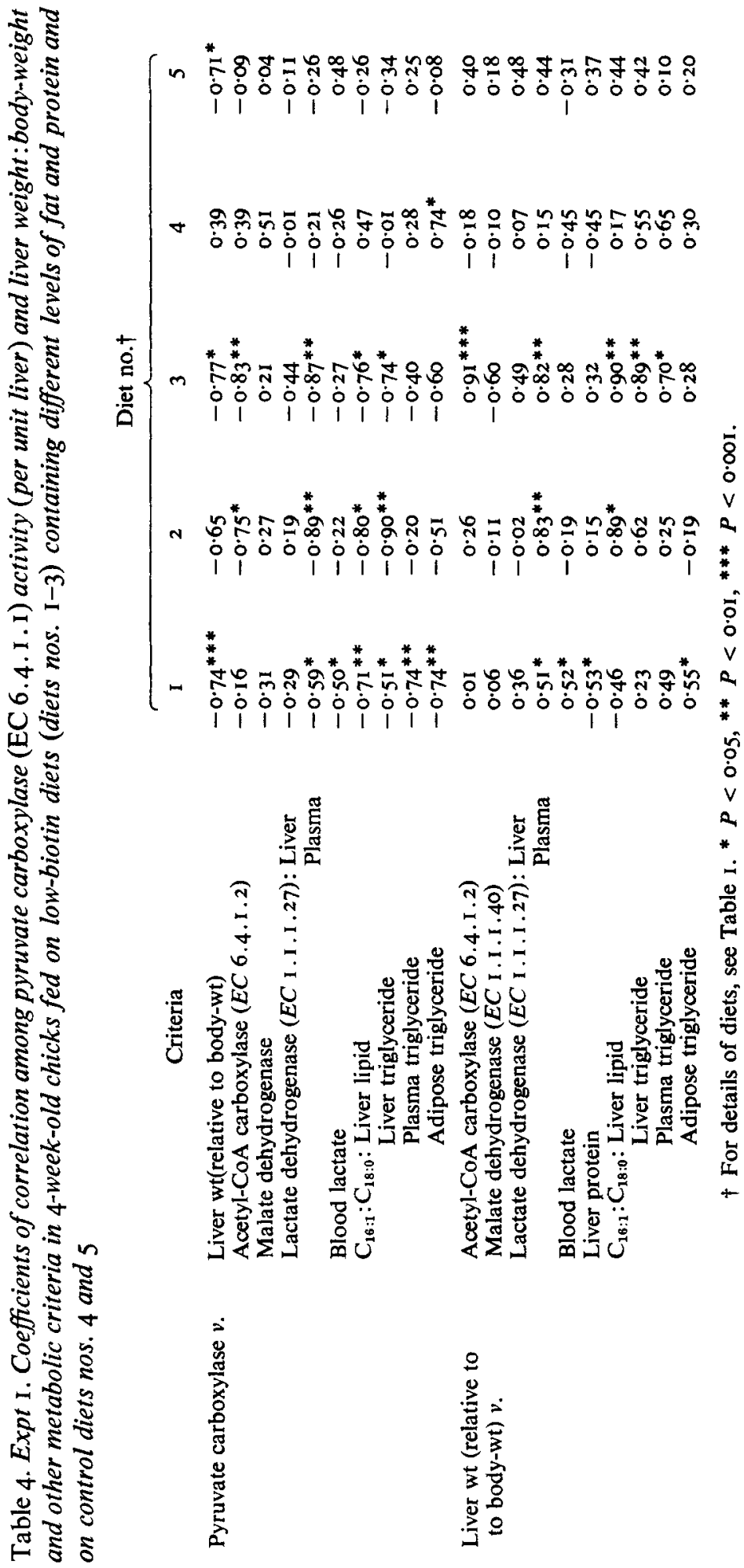


$\mathrm{C}_{18: 1}: \mathrm{C}_{18: 0}$ values were significantly higher $(P<0.05)$ in birds fed on diet no. I than in all others and, in adipose tissue, the values for birds fed on diets nos. 2 and 3 were also higher than that of the controls. With diet no. I, both plasma and adipose $\mathrm{C}_{18: 1}: \mathrm{C}_{18: 0}$ values were significantly higher $(P<0.05)$ in birds with low liver pyruvate carboxylase specific activity. Plasma lactate dehydrogenase specific activity was also $40 \%$ higher in this group, although the difference did not attain statistical significance $(0.1>P>0.05)$.

Correlation coefficients were calculated among all the criteria within all diets. Most of the statistically significant correlations involved either pyruvate carboxylase specific activity or liver weight and the relevant correlations involving these criteria are given in Table 4; other correlations involving them were not significant. With diet no. I there were significant negative correlations between pyruvate carboxylase and (a) liver weight as a proportion of body-weight, $(b)$ plasma lactate dehydrogenase specific activity, $(c)$ blood lactate and $(d)$ the $\mathrm{C}_{16: 1}: \mathrm{C}_{18: 0}$ values in the four lipids analysed. Some of them were also significant with diets nos. 2 and 3 , and in addition there were negative correlations with acetyl-CoA carboxylase. In contrast, only one correlation with pyruvate carboxylase attained statistical significance $(P<0.05)$ in each of the control diets. With diet no. I, liver weight was significantly correlated with plasma lactate dehydrogenase, blood lactate, liver protein and adipose tissue triglyceride $\mathrm{C}_{16: 1}: \mathrm{C}_{18: 0}$ as well as with pyruvate carboxylase. Plasma lactate dehydrogenase and some of the $C_{16: 1}: C_{18: 0}$ values with diets nos. 2 and 3 were significantly correlated with liver weight but there were no significant correlations within the control diets.

Because of the variability in liver weight, the correlation coefficients were also calculated after correcting for liver weight and body-weight. Thus total liver pyruvate carboxylase activity, as a proportion of body-weight, was significantly negatively correlated with liver weight: body-weight, liver malate dehydrogenase and protein, plasma lactate dehydrogenase and the four $\mathrm{C}_{16: 1}: \mathrm{C}_{18: 0}$ values with diet no. I. With diet no. 3 it was correlated with liver weight:body-weight, liver lactate dehydrogenase, acetyl-CoA carboxylase and protein, plasma lactate dehydrogenase and liver lipid and triglyceride $\mathrm{C}_{16: 1}: \mathrm{C}_{18: 0}$. In contrast, there were fewer significant correlations involving this criterion with diets nos. 2, 4 and 5 .

\section{Expt 2}

During the rearing stage, three of the twenty birds fed on diet no. I died from FLKS before $28 \mathrm{~d}$ of age. At $28 \mathrm{~d}$, two birds were showing clinical signs of FLKS (category IV, Whitehead, 1975) after the $6 \mathrm{~h}$ fast. These birds, together with a further four, were found to be hypoglycaemic and all six showed lesions characteristic of FLKS upon histological examination. Blood lactate and glucose concentrations are given in Table 5 and show that the mean lactate concentrations before the fast were significantly higher $(P<0.05)$ in birds fed on diet no. I than in the controls. The initial lactate concentrations in the blood samples from birds which subsequently developed FLKS were higher than those of birds fed on diet no. I, which remained healthy, although the difference was not statistically significant $(P>0.05)$. Among the six FLKS birds, initial lactate concentrations of four birds were above the initial group mean, one value was equal to it and the other value was below the mean. Of the eleven unaffected birds, four had initial lactate concentrations above the group mean. After the $6 \mathrm{~h}$ fast, lactate concentration had decreased in controls and unaffected birds but had increased markedly in all FLKS birds.

\section{Expt 3}

Measurements of plasma glucose concentrations confirmed that none of the birds in this experiment were suffering from FLKS at the start of the fast. However, during the fast two birds died and after $6 \mathrm{~h}$ a further three birds were showing severe clinical signs of FLKS 
.

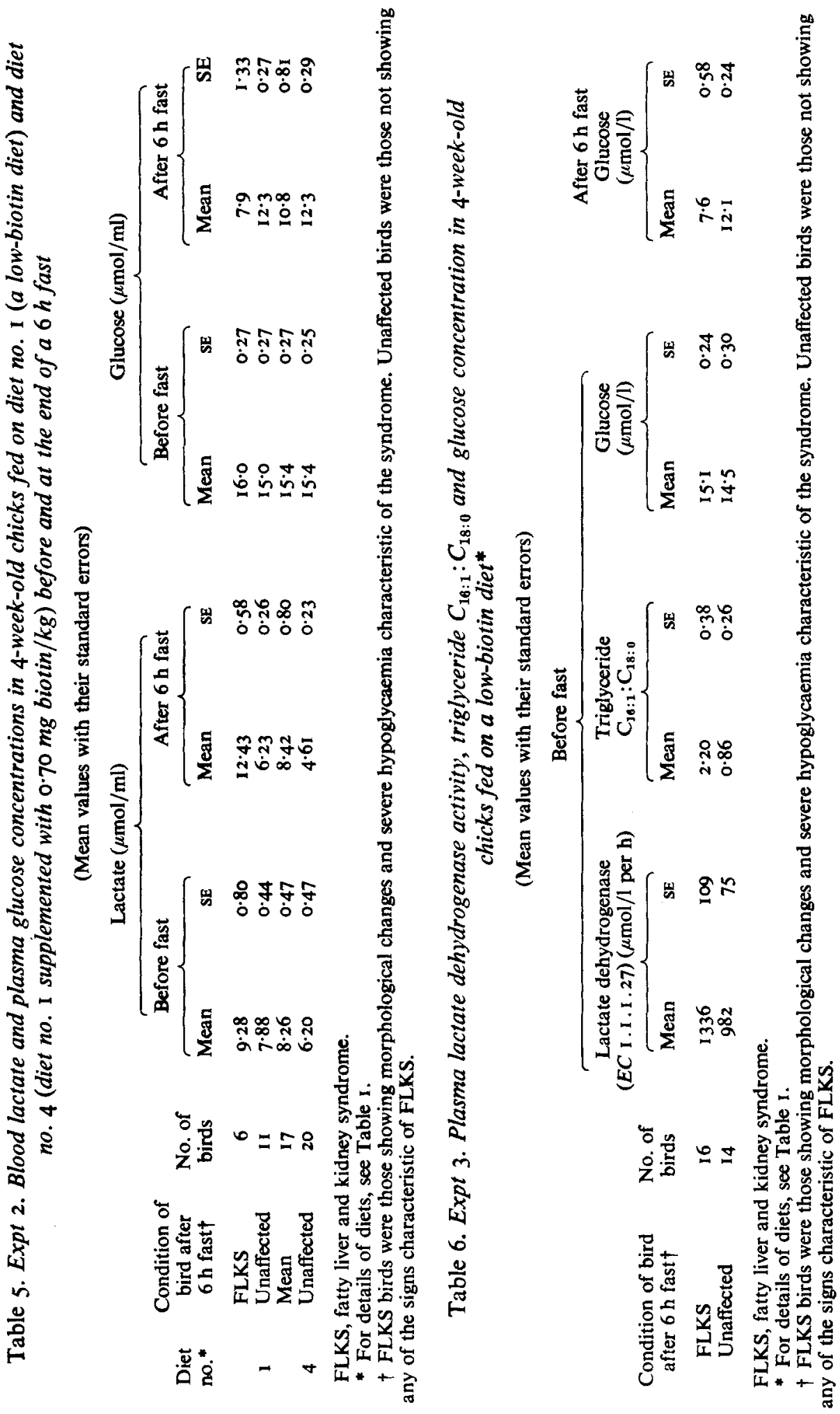


(category IV, Whitehead, 1975). These three birds were found to be severely hypoglycaemic (plasma glucose $<6.9 \mu \mathrm{mol} / \mathrm{l}$ ) and a further eleven birds were slightly hypoglycaemic (plasma glucose $<1 \mathrm{I} \cdot 0 \mu \mathrm{mol} / \mathrm{l}$ ). All these birds showed liver and kidney lesions typical of FLKS upon histological examination and a total of sixteen birds were thus assigned to the FLKS category. The remainder of the birds were clinically and histologically normal.

As is shown in Table 6, plasma lactate dehydrogenase specific activities before the fast were significantly higher $(P<0.01)$ in birds which subsequently developed FLKS than in those unaffected. Only three birds which developed FLKS had enzyme activities below I $000 \mu \mathrm{mol} / \mathrm{h}$ per I and only three unaffected birds had activities above this level.

The values for $\mathrm{C}_{18: 1}: \mathrm{C}_{18: 0}$ in plasma triglycerides were very significantly higher $(P<$ 0.001 ) among birds which developed FLKS. The value was less than I: $I$ in only one bird in this group but higher than one in three unaffected birds.

\section{DISCUSSION}

A comparison of the effects of a marginal biotin deficiency in diets associated with high and low incidences of FLKS indicates that there are several metabolic changes associated with the development of susceptibility in chicks to FLKS. Liver pyruvate carboxylase activity, which is known to be centrally involved in the syndrome, was much lower in birds fed on diet no. I, the diet that caused a high incidence of FLKS, than in birds fed on the other diets. Liver weights relative to body-weight and plasma lactate dehydrogenase activity were increased with diet no. I. The effect of diet on blood lactate concentration was less clear-cut, because although it was significantly higher with diet no. I than in controls, it was also high with diet no. 2, which caused little incidence of FLKS.

Significant changes occurred in the fatty acid compositions of several lipids. The $\mathrm{C}_{\mathbf{1 6 : 1}}$ : $\mathrm{C}_{18: 0}$ values were increased in liver lipids, especially triglycerides, of birds fed on diet no. I and this was reflected in corresponding changes in adipose tissue and plasma triglyceride compositions. In contrast, these changes were not so apparent in birds fed on the other lowbiotin diets (diets nos. 2 and 3 ). These results are consistent with the observations of Whitehead, Bannister, Evans, Siller \& Wight (I976) that the effect of biotin deficiency on tissue fatty acid composition is less pronounced as dietary fat or protein levels increase.

Effects of diet on other liver criteria were also observed. The activities of lactate dehydrogenase and malate dehydrogenase were significantly lower with all low-biotin diets than with control diet no. 4. Malate dehydrogenase was especially depressed in birds fed on the diets supplemented with fat or protein and this is consistent with the decreases in lipogenesis associated with such dietary changes (Yeh \& Leveille, 1969; Yeh, Leveille \& Wiley, 1970). Acetyl-CoA carboxylase was significantly higher with diet no. I than with control diet no. 5, although the differences between other diets were not significant. Liver protein level was increased with the low-biotin diets but lipid level was unaffected by diet.

The relationships between the principal criteria were investigated. Results from the birds fed on diet no. I were assigned to one of two groups ('low' and 'high', as described previously). Plasma lactate dehydrogenase activity and the $\mathrm{C}_{16: 1}: \mathrm{C}_{18: 0}$ values in all the lipids analysed were significantly higher in the 'low' group. Liver weight:body-weight, blood lactate concentration and acetyl-CoA carboxylase activity were also increased, though not significantly so.

The interrelationships between the criteria were also studied by calculating the regression coefficients within diets. With diet no. I pyruvate carboxylase activity was significantly correlated with liver weight: body-weight, plasma lactate dehydrogenase, blood lactate and $\mathrm{C}_{16: 1}: \mathrm{C}_{18: 0}$ in the four lipids. These correlations were also significant with the other lowbiotin diets, as was the correlation with acetyl-CoA carboxylase. Compared with pyruvate 
carboxylase, liver weight:body-weight was involved in fewer significant correlations with diet no. I and was not correlated with any of the liver enzymes apart from pyruvate carboxylase. The correlations involving pyruvate carboxylase were also significant after correcting for liver and body-weights, demonstrating that they were not artefacts of variations in liver and body-weights.

Although the relationships between metabolic criteria were thus similar on all low-biotin diets, the magnitudes of the criteria involved in significant correlations were more extreme with diet no. I than with the other two diets. Liver pyruvate carboxylase activity in particular could be very variable and since it was correlated with several plasma criteria that could be measured without killing the bird, further experiments (Expts 2 and 3) were carried out to test the hypothesis that it was the birds with low pyruvate carboxylase activity which were most susceptible to FLKS. The blood criteria measured in birds given diet no. I before the induction of FLKS by fasting were blood lactate, and plasma lactate dehydrogenase and triglyceride $\mathrm{C}_{16: 1}: \mathrm{C}_{18: 0}$. Of these, the criterion least well correlated with pyruvate carboxylase was lactate, and although two-thirds of the birds developing FLKS during or after fasting had initial lactate levels above the group mean, this represented only half the birds with high initial lactate levels. Compared with lactate, plasma lactate dehydrogenase gave a better indication of the possibility of a bird developing FLKS : $81 \%$ of affected birds had initial activities of $>1000 \mu \mathrm{mol} / \mathrm{h}$ per I whereas only $21 \%$ of those unaffected had activities above this value. Of the three criteria, plasma triglyceride $C_{16: 1}: C_{18: 0}$ was the most closely correlated with pyruvate carboxylase activity and gave the best indication of susceptibility to FLKS. This value was greater than I in $94 \%$ of affected birds and in only $21 \%$ of those unaffected.

The results show that it is possible to predict which birds are most likely to develop FLKS when suitably challenged and are also consistent with the theory that the birds which develop the syndrome are those with very low liver pyruvate carboxylase activities. The actual activities of some birds fed on the FLKS-inducing diet were very low indeed: in one bird the activity was not measurable, in others it was 11,13 and $14 \mu \mathrm{mol} / \mathrm{h}$ per $\mathrm{g}$. These values are lower than the activities quoted for birds clinically affected with FLKS ((mean $\pm \mathrm{SE}) 4 \mathrm{I} \pm 3.4 \mu \mathrm{mol} / \mathrm{h}$ per $\mathrm{g}$, Bannister, $1976 \mathrm{~b}$ ) but nevertheless none of the birds showed any clinical signs of the syndrome. It is thus apparent that, although FLKS occurs in birds which have little or no gluconeogenic capacity via pyruvate carboxylase because of a dietary insufficiency of biotin, they can, under normal circumstances, live and indeed thrive in the virtual absence of this enzyme, their requirement for gluconeogenesis being presumably met by pathways independent of it. Since pyruvate carboxylase activity can be so low in the absence of FLKS, it is unlikely that the initiation of the syndrome need be associated with a further decrease in activity. Instead, it is more likely that initiation of the syndrome caused by stress (or fasting) may be due to inhibition of an alternate pathway of gluconeogenesis. Support for this suggestion comes from the observation that gluconeogenesis from glycerol in vitro is inhibited in FLKS and is associated with an altered redox state of the liver (Bannister \& Cleland, 1977). When the supply of glucose thus becomes inadequate, hypoglycaemia and the consequent clinical signs of FLKS then ensue.

Some of the findings are in agreement with those of Hood et al. (1976) who also found that a marginal biotin deficiency could result in low liver pyruvate carboxylase activities and increases in liver size and blood lactate level. However, using an unspecified broiler strain and different diets, they found increased hepatic activities of acetyl-CoA carboxylase and malate dehydrogenase in birds with large livers not clinically affected with FLKS and concluded that the livers became enlarged and hyperfunctional in an attempt to metabolize pyruvate by pathways independent of pyruvate carboxylase, e.g. lipogenesis. In the present studies, malate dehydrogenase was found to be depressed by the low-biotin diets and was 
not correlated with liver size. Mean acetyl-CoA carboxylase activity was higher in birds with low pyruvate carboxylase activities, but the difference was not statistically significant and was heavily influenced by one very high value, with the result that there was no significant correlation between the activities of the two enzymes. These findings are consistent with those of Balnave \& Pearce (1976). Although we thus agree that enlargement of the liver is associated with a decrease in pyruvate carboxylase activity in birds fed on marginally biotin-deficient diets, we have not obtained any evidence that the enlargement is associated with an increase in the activities of enzymes associated with alternate pathways for metabolizing pyruvate although the rate of flux through these pathways has not been measured in vivo by either group of workers.

Our studies also explained the role of dietary fat and protein in reducing the incidence of FLKS because birds fed on diets nos. 2 and 3, the diets supplemented with fat and protein respectively but containing the same amount of biotin as diet no. I, had higher mean pyruvate carboxylase activities than those fed on diet no. I. Balnave, Cumming \& Sutherland (1976) have also shown this effect of fat. The occasional occurrence of FLKS with these diets is explained by the variation in individual enzyme activities. For example, one bird fed on diet no. 3 had an activity of $36 \mu \mathrm{mol} / \mathrm{h}$ per $\mathrm{g}$, a level sufficiently low to render it susceptible to FLKS. As a confirmation of the findings with diet no. I, this bird also had a high plasma lactate dehydrogenase activity $(2603 \mu \mathrm{mol} / \mathrm{h}$ per 1$)$, a high plasma triglyceride $\mathrm{C}_{16: 1}: \mathrm{C}_{18: 0}$ $(2.5)$ and a large liver ( $50 \mathrm{~g} / \mathrm{kg}$ body-weight).

Increased dietary fat or protein levels are known to reduce lipogenesis (Yeh \& Leveille, 1969; Yeh et al. 1970) which might reduce the amount of biotin required for acetyl-CoA carboxylase activity. Beacuse it is a cytoplasmic enzyme, acetyl-CoA carboxylase might have freer access to the available biotin than the intra-mitochondrial pyruvate carboxylase; hence a decrease in acetyl-CoA carboxylase might leave more biotin available for pyruvate carboxylase. The measured activities of acetyl-CoA carboxylase were less with diets nos. 2 and 3 than with diet no. I, although the differences were not significant. However, with both diets nos. 2 and 3, there were significant negative correlations between the two enzymes, a finding consistent with the above hypothesis.

The findings of this study and their interpretation suggest that FLKS may be considered to be a biotin-deficiency condition, albeit not a simple one. Similar relationships occur between the metabolic criteria with different types of low-biotin diet although the extent of the various changes brought about by biotin deficiency are affected by other dietary constituents. When these other factors combine to maximize the effect of the deficiency on liver pyruvate carboxylase activity, the birds become susceptible to FLKS. Thus FLKS is part of the spectrum of biotin deficiency, although its actual occurrence is also dependent on environmental factors.

The authors thank Drs W. G. Siller and P. A. L. Wight for the histological diagnoses of FLKS, Mrs C. C. McCorquodale and Mr P. W. Teague for assistance with the design of the experiment and analyses of results, Mr J. Armstrong, Miss A. J. Campbell and Mrs C. E. McNeill for technical assistance and Hoffman-La Roche \& Co., Basle, for biotin analyses.

\section{REFERENCES}

Balnave, D., Cumming, R. B. \& Sutherland, T. M. (I976). Aust. vet. J. 52, 433.

Balnave, D. \& Pearce, J. (1976). Br. Poult. Sci. 17, 627.

Bannister, D. W. (1976a). Comp. Biochem. Physiol. 53B, 575.

Bannister, D. W. (1976b). Biochem. J. 156, I67.

Bannister, D. W. \& Cleland, M. E. (I977). Int. J. Biochem. 8, 89.

Bannister, D. W., Evans, A. J. \& Whitehead, C. C. (1975). Res. vet. Sci. 18, 149. 
Bergmeyer, H. U. \& Bernt, E. (1974). In Methods of Enzymatic Analysis, p. 574 [H. U. Bergmeyer, editor]. London and New York: Academic Press.

Blair, R. \& Whitehead, C. C. (1974). Proc. XV Wld's Poult. Congr., New Orleans, p. 380.

Christie, W. W., Noble, R. C. \& Moore, J. H. (I970). Analyst, London. 95, 940.

Czok, R. \& Lamprecht, W. (1970). In Methoden der enzymatischen Analyse, 2nd ed., p. 1407 [H. U. Bergmeyer, editor]. Neinheim: Verlag Chemie.

Evans, A. J., Bannister, D. W., Whitehead, C. C., Siller, W. G. \& Wight, P. A. L. (1977). Res. vet. Sci. 23, 275.

Folch, J., Lees, N. \& Sloane Stanley, G. H. (1957). J. biol. Chem. 226, 497.

Hohorst, H. J. (1963). In Methods of Enzymatic Analysis, p. 266 [H. U. Bergmeyer, editor]. London and New York: Academic Press.

Hood, R. L., Johnson, A. R., Fogarty, A. C. \& Pearson, J. A. (1976). Aust. J. biol. Sci. 29, 429.

Lohr, J. E. (1975). N.Z. vet. J. 23 , I67.

Lowry, O. H., Rosebrough, N. J., Farr, A. L. \& Randall, R. J. (195I). J. biol. Chem. r93, 265.

Morley, G., Dawson, A. \& Marks, V. (1968). Proc. Ass. clin. Biochem. 5, 42.

Payne, G. G., Gilchrist, P., Pearson, J. A. \& Hemsley, L. A. (1974). Br. Poult. Sci. 15, 489.

Sutherland, E. W. \& Waselait, W. D. (1956). J. biol. Chem. 218, 459.

Whitehead, C. C. (1975). Res. vet. Sci. 18, 32.

Whitehead, C. C., Bannister, D. W., Evans, A. J., Siller, W. G. \& Wight, P. A. L. (1976), Br. J. Nutr. 35, I 5.

Whitehead, C. C. \& Blair, R. (1974). Wld's Poult. Sci. J. 30, 231.

Whitehead, C. C. \& Blair, R. (1976). Res. vet. Sci. 2I, 141 .

Whitehead, C. C., Blair, R., Bannister, D. W. \& Evans, A. J. (1975). Res. vet. Sci. r8, 100.

Whitehead, C. C., Blair, R., Bannister, D. W., Evans, A. J. \& Jones, R. M. (1976). Res. vet. Sci. $20,180$.

Wight, P. A. L. \& Siller, W. G. (1975). Res. vet. Sci. 19, 173.

Wise, E. M. \& Ball, E. G. (1964). Proc. natn. Acad. Sci. USA 52, 1255.

Wright, L. D. \& Skeggs, H. R. (1944). Proc. soc. exp. Biol. Med. 56, 95.

Yeh, Y.-Y. \& Leveille, G. A. (1969). J. Nutr. 98, 356.

Yeh, Y.-Y., Leveille, G. A. \& Wiley, J. H. (1970). J. Nutr. 100, 917. 